\title{
The Influence of Negative Personality Factors on Choice of Humor: A Study on Undergraduate Students
}

\author{
Siddoju Aishwarya ${ }^{1 *}$
}

\section{ABSTRACT}

The present study explored the correlations between the four humor styles and the Dark Triad traits of personality. Participants were 202 undergraduates from India who finished the humor Styles Questionnaire, the Narcissistic Personality Inventory, the Self-Report Psychopathy Scale, and the MACHIV. Results intimated that member who scored higher on sub-clinical psychopathy and Machiavellianism exhibited a more inclination to utilise negative humor styles (self-defeating and aggressive). whereas, individuals who got higher scores on narcissism were progressively inclined to have a preference toward affiliative humor or style and self-enhancing humor style and they negatively correlated with negative humor styles. The study was conducted to help understand the personality traits of individuals with various genre of humor and help to explain the nature of the Dark Triad traits of personality. It said to shed light on the interpersonal styles employed by people who exhibit these attributes.

\section{Keywords: Humor Styles, Psychopathy, Narcissism, Machiavellianism}

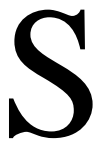
ense of humor refers to a person's capacity to capture aesthetic aspects of humor. (Martin, 2007). It is, therefore, not difficult to understand why how of humor remains considered a socially desirable characteristic. Moreover, it influences the relations we establish with others, and our kinds of communication and persuasion; humor can function a kind of aggression or as a coping mechanism or even both at the same time. Martin, 2007).

Based on previous research (e.g., Hehl \& Ruch, 1985), we understand humor as a stable personality tendency concerning a sensation, to a behavior, to use it as a coping, to a capability, and finally, to an aesthetic sense. Obviously, the conception of humor implies that people will more often tend to present a "state" of humor or an emotion made up of the subjective feeling of hilarity or amusement, the expression of laughter and Duchenne smiling, the associated physiological and motor response, and greater exposure to, reactivity to and productivity of comic and humorous stimuli.

Associations between humor styles and personality: Humor styles theory-The relations between humor and personality have been analysed by various authors, including

\footnotetext{
${ }^{1}$ Research Scholar, Department of Psychology, English, and Journalism, Loyola Academy, Hyderabad, Telangana, India *Corresponding Author

Received: September 09, 2021; Revision Received: November 25, 2021; Accepted: December 08, 2021 (C) 2021, Siddoju A.; licensee IJIP. This is an Open Access Research distributed under the terms of the Creative Commons Attribution License (www.creativecommons.org/licenses/by/2.0), which permits unrestricted use, distribution, and reproduction in any Medium, provided the original work is properly cited.
} 


\section{The Influence of Negative Personality Factors on Choice of Humor: A Study on Undergraduate Students}

Eysenck, Cattell, McGee and Ruch. However, the perspective of Martin et al.(2003) can be considered the most influential in current self-evaluative research. They distinguished different types of humor that could be analysed through an instrument that was better compared to its predecessors - for measuring the relations between mental health, emotions and humor. The intrapersonal aspect would be associated with amusement, and would also involve the capacity to cope with stress and make use of humor as a defence mechanism. (Ziv, 1984).

Machiavellianism is a concept developed by Richard Christe and his associates (Christie and Geis,1970), their research depends on thoughts of an Italian political advisor and philosopher Niccolo Machiavelli (1530). Nowadays, a Machiavellian person is taken into account to be endowed with practical intelligence, emotional control, and really high achievement motivation, dropping the negative connotation. (Pastor, 1982) Machiavelli has been viewed as a political devil, advising leaders to embrace the humanities of treachery, force and cruelty so as to achieve success. The Prince (1513)

Psychopathy was first described by Hervey Cleckley in 1941, and later elaborated on by Robert Hare in the 1980s and early 1990s, as a condition marked by interpersonal, affective, and behavioural deficits, additionally as potentially antisocial characteristics. (Hare, 1991 Interpersonal traits include such characteristics as superficial charm, grandiosity, manipulation, and deceit. Affective characteristics include shallow affect and an absence of remorse and empathy. (PCL-R; Hare, 1991) The Psychopathy Checklist and its revised version reflect this possibility with a predominantly personality-based factor and a largely behaviour-based factor. It has led to the development of shorter self-report instruments i.e., is the Levenson et al. (1995) Self-Report Psychopathy Scale (LSRP; Levenson et al., 1995

The term narcissism was first introduced in psychological literature within the 1898, when Havelock Ellis used the term Narcissus-like to refer to "a tendency for the sexual emotions to be lost and almost entirely absorbed in self-admiration". (Ellis, 1898). On the one hand, narcissism served as an aid for his meta-psychological theorizing, Narcissism is characterized by exaggerated self-image, poor self-regulation, and poor relational functioning. (e.g., Fine, 1986; Moore, 1975; Sandier, Holder, \& Dare, 1976; Tiecholz, 1978). From the adaptive perspective, narcissism helps individuals to thrive and increases their sense of private agency, thereby increasing personal well-being. (Pincus, Ansell, Pimentel, Cain, Wright, \& Levy, 2009),

\section{METHODOLOGY}

\section{Sample}

The sample comprised of two hundred two undergraduates (121 women and 83 men) from various colleges in around Hyderabad. The study had been carried out on the basis of quantitative research design. The sample was selected by the methods of convenience sampling and snowball sampling. Data collection was done through online and offline methods of distribution of questionnaires using google forms and documents.

\section{Instruments}

Four measures were used in this study,

1. Humor Styles Questionnaire (HSQ): The 32-item HSQ (Martin et al., 2003) was used to assess individual differences in the four humor styles (affiliative, selfenhancing, aggressive, self-defeating). Participants responded to self-reflective 
statements pertaining to these humor styles via a 7-point Likert Scale (where $1=$ totally disagree and $7=$ totally agree).

Reliabilities of the humor style scales are .81 for self-enhancing humor, .80 for affiliative and self-defeating humor, and .77 for aggressive humor (Martin et al., 2003).

2. Narcissistic Personality Inventory (NPI): The NPI (Raskin \& Hall, 1979) consists of 40 forced-choice items measuring individual differences in sub-clinical narcissism. Participants completed each item by selecting one of two polar self-reflective statements that best described them. The NPI has demonstrated good psychometric properties (Jakobwitz \& Egan, 2006).

3. Levenson Self-Report Psychopathy (LSRP) Scale: The LSRP is a 26-item selfreport measure of psychopathy. Items are scored on a 1 (Disagree Strongly) to 4 (Agree Strongly) scale.

- Psychometric properties: Coefficient alphas for the LSRP total score (26 items), F1 (16 items), and F2 (10 items) were .83, .82, and .61, respectively. The lower alpha for $F 2$ is quite consistent with previous studies of this measure: Hicklin and Widiger $(2005 ; \alpha=.66)$. Lynam et al. $(1999 ; \alpha=.68)$, Miller, Lynam, Widiger, and Leukefeld (2001; $\alpha=.63)$, and Ross et al. (2004; $\alpha$ $=.62$ ).

4. MACH-IV: The MACH-IV (Christie \& Geis, 1970) was used to assess individual differences in Machiavellianism. This measure consists of 20 items presented as selfreflective statements. Participants responded to the items by indicating the extent to which they agreed with each statement on a 5-point Likert Scale (where $1=$ disagree strongly and $5=$ agree strongly). Prior studies have shown that the MACH-IV possesses good psychometric properties (e.g., Wrightsman, 1991)

\section{Procedure}

Participants completed measures of The Humor Styles Questionnaire (HSQ; Martin et al., 2003), Narcissistic Personality Inventory (NPI, Raskin \& Hall, 1979), The MACH-IV (Christie \& Geis, 1970) and the Levenson Self-Report Psychopathy (LSRP) Scale. Instructions were already typed out in the questionnaire booklet and their personal information such as name, age, course they are studying, name of the institution were collected and a signed consent form was also attached to it. The responses were transformed into scores and had been added to excel for statistical analysis.

The research data was analysed statistically by using the Pearson correlation method as per the need of the study to measure the correlation between two variables among undergraduate students. Furthermore, to test the significance of the correlation coefficients, one tailed test was calculated to find the significance.

RESULTS

Table No. 1 Correlations between Humor Styles and The Dark Triad Traits variables.

\begin{tabular}{|l|l|l|l|}
\hline \multirow{2}{*}{ Humor Styles } & \multicolumn{2}{|l|}{ Dark Triad Traits } \\
\cline { 2 - 4 } & Machiavellianism & Psychopathy & Narcissism \\
\hline Affiliative & $-0.25^{* *}$ & 0.00 & $0.17^{*}$ \\
\hline Self-Enhancing & -0.27 & $-0.19^{*}$ & $0.24^{* * *}$ \\
\hline Aggressive & $0.16^{*}$ & $0.20^{* *}$ & -0.10 \\
\hline Self-Defeating & 0.10 & $0.17^{*}$ & -0.01 \\
\hline
\end{tabular}

Significance $=* p<.05(1$-tailed $), * * p<.01$ (1-tailed $), * * * p<.001(1$-tailed $)$

(C) The International Journal of Indian Psychology, ISSN 2348-5396 (e)| ISSN: 2349-3429 (p) | 1340 


\section{The Influence of Negative Personality Factors on Choice of Humor: A Study on Undergraduate Students}

The correlations between the humor styles and the dark triad traits of personality are mentioned in the table. Proving the hypothesis, Machiavellianism and psychopathy positively correlated with the negative humor styles, I.e., aggressive and self-defeating humor styles, it has also been observed that there was a negative correlation between Machiavellianism and affiliative humor style and self-enhancing humor style. It has been inferred from Table1 that psychopathy and self-enhancing humor are negatively correlated and positively with affiliative humor style, although the values obtained show a weak correlative value.

Narcissism positively correlated with affiliative and self-enhancing humor styles which had also proved to be significant by using the 1 tailed test. It is also been found that Narcissism and negative humor styles have been negatively associated and there is no correlation between narcissism and the humor styles, although the correlation is not significant and have a weak correlative value.

\section{DISCUSSION}

The current study investigated correlations between humor styles and the dark triad traits of personality. The majority of the hypotheses mentioned were supported. Psychopathy and Machiavellianism positively correlated with both the negative humor styles which are aggressive and self-defeating humor styles, and negatively correlated with the positive humor styles i.e., affiliative and self-enhancing humor styles. While the narcissistic traits negatively correlated with negative humor styles indicating that there is no correlation between them and as predicted it had positively correlated with positive humor styles.

The correlations found between Machiavellianism, psychopathy and negative styles of humor were expected, based on the fact that the constructs share several higher order and lower order personality correlated. (e.g., Vernon, Martin et al.,2008; Vernon et al., 2009). The correlations between psychopathy, Machiavellian and the aggressive humor styles were particularly strong and significant when one tailed t test was done. It may attribute to the components of these three constructs, specially, aggressive humor is defined, in part, by the intention to manipulate others through disparaging jokes or threats (Martin et al., 2003). Machiavellianism is defined largely by interpersonal manipulative behaviour that are carried out for personal success. This suggests that Machiavellian individuals may employ aggressive humor as a form of controlling others for personal gain.

Aggressive humor style that is more relevant to psychopathic traits is the idea that it expresses humor without any regard to others values or emotions, it is delivered to attack an individual's insecurities or to criticize others on topics that the person doesn't believe in. these components of impulsivity and social unawareness are relevant to theories of psychopathy. It may also suggest the lack of conscience and moral code that the person might lack while using aggressive humor.

This also suggests that psychopathic behaviours stem from poor behavioural inhibition (Gray,1970) and the inability to gauge people's emotions and the incompetency of not being able to feel emotions and need of more stimulation than the average person. (e.g.,MullinsNelson, Salekin, \& Leistico, 2006). Thus, to conclude, the observation that people with high scores in psychopathic traits employ aggressive humor style because of the lack of care about the impact on others. 


\section{The Influence of Negative Personality Factors on Choice of Humor: A Study on Undergraduate Students}

As per the hypotheses stated, the only dark triad to correlate with positive humor styles is narcissism. The relationship with self-enhancing humor and affiliative humor was predicted based on the number of personality correlates shared by the constructs. (e.g., Vernon, Martin et al., 2008; Vernon et al., 2009). In particular, narcissism and positive humor styles have been linked to the Big Five factors of Extraversion, which implies that both entail behaviours such as assertiveness, gregariousness, and interpersonal warmth geared towards creating interpersonal bonds. Furthermore, narcissistic individuals use self-enhancing and affiliative humor styles to heighten their self-esteem, increase their popularity among peers and seek validation. Previous studies have linked narcissism to greater optimism (e.g., Hickman et al., 1996), and to less intense emotional responding to negative life events (e.g., Zuckerman \& O'Loughun, 2009) all the qualities reminiscent of the self-enhancing humor style. Although an optimistic persona of narcissistic individuals, they also have been shown to become hostile when their sense of self is threatened. (e.g., Witte, Callahan, \& Perez-Lopez, 2002). Opposingly, their ability to maintain a positive perspective does not appear to extend to other aspects of their lives, which may negate the relationship between the positive humor style.

Previous research had also found similar results for their population samples, which reflects the relationship between the humor styles and dark triad traits may be valid across countries and cultures. The use of humor has always been present in an individual's life. the development of technology and media has also had an impact on the population being more exposed to humor through internet and social media. In the age where stand-up comedy is idealized and the Indian youth being influenced by the humor and having their own preference.

\section{REFERENCES}

Christie, R., \&Geis, F.L. (1970). Studies in Machiavellianism. New York, NY: Academic.

Cleckley, H. (1941). The mask of sanity (1st ed.). St. Louis, MO: Mosby

Ellis, H. (1898). Auto-eroticism: A psychological study. Alienist and Neurologist, 19,260-299.

Fine, R. (1986). Narcissism, the self and society. New York: Columbia University Press.

Gray, J. A. (1970). The psychophysiological basis of introversion-extraversion. Behaviour research and therapy, 8(3), 249-266.

Hare, R. D. (1991). The Hare Psychopathy Checklist-Revised PCL-R. Toronto, Canada: Multi-Health Systems.

Hare, R. D. (2003). The Hare Psychopathy Checklist-Revised (PCL-R) (2nd ed.). Toronto, Canada: Multi-Health Systems

Hehl, F. J., \& Ruch, W. (1985). The location of sense of humor within comprehensive personality spaces: An exploratory study. Personality and Individual Differences, 6(6), 703-715.

Hickman, S. E., Watson, P. J., \& Morris, R. J. (1996). Optimism, pessimism, and the complexity of narcissism. Personality and Individual Differences, 20(4), 521-525.

Levenson, M. R., Kiehl, K. A., \& Fitzpatrick, C. (1995). Assessing psychopathic attributes in a non-institutionalized population. Journal of Personality and Social Psychology, 68, 151-158. doi:10.1037/0022-3514.68.1.151

Machiavelli, N. (1993). The prince (1513). Hertfordshire: Wordsworth Editions.

Martin, R. A. (2007). The psychology of humor: An integrative approach. Burlington, MA: Elsevier Academic Press.

Moore, B. E. (1975). Toward a clarification of the concept of narcissism. Psychoanalytic Study of the Child, 30, 243-276.

(C) The International Journal of Indian Psychology, ISSN 2348-5396 (e)| ISSN: 2349-3429 (p) | 1342 


\section{The Influence of Negative Personality Factors on Choice of Humor: A Study on Undergraduate Students}

Mullins-Nelson, J. L., Salekin, R. T., \& Leistico, A. M. R. (2006). Psychopathy, empathy, and perspective-taking ability in a community sample: Implications for the successful psychopathy concept. International Journal of Forensic Mental Health, 5(2), 133-149.

Pastor, 0. (1982). Síndromefrío de personalidad sagaz. Psicología social del maquiavelismo. Salamanca, Spain: Bibliotheca Salmanticensis

Raskin, R. N., \& Hall, C. S. (1979). A narcissistic personality inventory. Psychological reports.

Sandier, J., Holder, A., \& Dare, C. (1976). Frames of reference in psychoanalytic psychology. British Journal of Medical Psychology, 49, 267-274.

Veselka, L., Schermer, J. A., Martin, R. A., \& Vernon, P. A. (2010). Relations between humor styles and the Dark Triad traits of personality. Personality and Individual Differences, 48(6), 772-774.

Witte, T. H., Callahan, K. L., \& Perez-Lopez, M. (2002). Narcissism and anger: An exploration of underlying correlates. Psychological Reports, 90(3), 871-875.

Yip, J. A., \& Martin, R. A. (2006). Sense of humor, emotional intelligence, and social competence. Journal of research in personality, 40(6), 1202-1208.

Ziv, A. (1988). Teaching and learning with humor: Experiment and replication. The Journal of Experimental Education, 57(1), 4-15.

Zuckerman, M., \& O'Loughlin, R. E. (2009). Narcissism and well-being: A longitudinal perspective. European Journal of Social Psychology, 39(6), 957-972.

\section{Acknowledgement}

The author appreciates all those who participated in the study and helped to facilitate the research process.

\section{Conflict of Interest}

The author(s) declared no conflict of interest.

How to cite this article: Siddoju A. (2021). The Influence of Negative Personality Factors on Choice of Humor: A Study on Undergraduate Students. International Journal of Indian Psychology, 9(4), 1338-1343. DIP:18.01.127.20210904, DOI:10.25215/0904.127 